\title{
Geographical Terms and Concepts as the Evidence of Material and Spiritual Culture of the Tatar Language
}

\author{
Denmukhametov R.R.
}

\author{
Kazan Federal University, Institute of Management, Economics and Finance, Kazan, 420008, Russia
}

Denmukhametova E.N.

Kazan Federal University, Institute of Institute of Philology and Arts, The Russian Federation, 420008, Kazan

\section{Doi:10.5901/mjss.2015.v6n3p777}

\section{Abstract}

This paper discusses the use of the geographical terms and concepts in the Tatar proverbs. The paper analyzes the general features of the Tatar proverbs and studies the geographical terms characteristics, embodied in the national and cultural peculiarities of the Tatar people. These terms and concepts are analyzed as lexical phenomena - metaphors, borrowings and synonyms. The lexical semantics is studied based on the example of the geodemographical term, which enabled for a vivid demonstration of the change in way of thinking, the view on the national identity from the antiquity to the present.

Keywords: vocabulary, geographical terms, nature, the Tatar language, mentality.

\section{Introduction}

As it is known, most of the vocabulary, indicating the natural phenomena appeared during the ancient times, has made a long way to the modern Tatar language without changing its semantic scope, whilst only adding to it. The language appears to be the main condition for the creation of an ethnic community. Being the foundation of the social existence, it brings people together, and due to its meaningfulness, it takes them to its domain, swerves the ethnicity and largely defines it. The ethnic identity is based on the native language and is implemented in it. Therefore, the basic concepts of a language give a general description of the ethnic group, define the unique individual look of the ethnic culture.

The geographical terms and concepts in the Tatar language are part of its active vocabulary, for, since times immemorial, the mankind has lived in a close contact with the environment and often used these concepts in the speech. The vocabulary, describing the nature and preserved from the ancient times, reveals the highlights influencing the formation of psychology of the Tatar national language personality, in which we clearly observe the reflexion of people's vision of the world, its national peculiarity, the settlement and migration conditions, its use on the farm and in recreation [1-5].

Based on the foregoing, it can be assumed that, depending on the social environment the perception of the world can alter, although the main features of the national outlook will remain unchanged [6-7]. Let us try to prove this thesis by providing the examples of the geographical terms and concepts in the Tatar language, genetically dating back to the ancient Turkic language and reflected in the Tatar paramiology.

\section{Methods and Resources}

The object of our study are the Tatar paremias, whereas the subject is the vocabulary denoting the geographical terms and concepts that are part of the active vocabulary of the Tatar literary language used both in the oral Tatar language and written communication. In our work we have used the descriptive and comparative methods, as well as the contextual, etymological analyzes to identify the most efficient forms of the vocabulary and their changes in the modern Tatar language.

The linguistic and cultural and the hermeneutical approaches to the study of the processes pertaining to the changes in the lexical items semantics allowed us to analyze the cultural status of lexical units denoting the geographical terms and concepts. At the same time we observed the thinking -patterns that led to the emergence and development of these semantic lexical items. 


\section{The Research Results}

Man always seeks to spiritualize everything that surrounds him. He can not imagine nature being dead and soulless. People constantly ascribe the features and aspirations inherent in their personality to all the objects of the surrounding world. Therefore, the division of natural beings and phenomena into the animate and inanimate is quite relative. This is particularly evident in proverbs; in fact one of the most remarkable phenomena in their poetics, is, no doubt, a figurative motivation of their content, the allegorical form of relaying the thought. The important role of paramiology in the spiritual life of an ethnic group is widely-known. For instance, proverbs and sayings make the so-called "folk layer" - the cultural and linguistic system containing unique ancient poetics based on metaphors, and accumulated wisdom of the nation in a variety of concise semantic formulas, reflecting all aspects of daily and spiritual life of many generations [8-9].

The geographical terms in the Tatar folk texts imply climatic features of a territory, terrain, water and living landscape components - such as the flora, fauna, soil. They are reflected to in $2 / 3$ of proverbs and are considered as animate and inanimate nature in philological studies.

Spiritualization of natural phenomena is particularly true for proverbs: Tamchy tama- tama kul bula // drop by drop make a lake, i.e. many small forms make a large one; Ber kukte ike ai bulmas // Two Moons do not shine in one sky, i.e someone has superiority over others, two do not occur in one monastery; Tamchyga tash chydamas // The stone gives in to the drop, i.e. persistence and patience win.

The figurative meaning is typical of all those sayings and realities taken from nature and its phenomena of flora and fauna, etc. Therefore, the description of the landscape, the characteristics of the natural phenomena, and even inanimate natural object in proverbs will be reflected through impersonation.

It is well known that the landscape, the terrain and the geological composition are reflected in the places' names of Tatarstan. More than 100 villages have names associated with a particular feature of the terrain. Since a long time ago people have noticed the peculiarities of the landscape they settled in and this reflected in the names of the settlements.

Describing the location, the area, the Tatar proverbs use such geographical terms as tau // mountain, chokyr // pit, kom // sand, kalku // hill, sazlyk // swamp, elga // river, dingez //sea, etc. Each of them has its own characteristics.

Tau //mountain is associated with an insurmountable obstacle, something difficult to overcome: Tauga karup, tau bulmah// Having looked at the mountain, do not be a mountain youself; Tauga menue kyen, toshue ansat // It is difficult to climb the mountain, but is easy to descend; Tau bulgach, chokyry bulla // If there is a mountain, then there's a pit. To describe the height of the mountain the assonance is used relayed via the lexical items chokyr // pit, or through such idioms as tau menu // climb up the mountain - tuben toshu // go down: Taudan tegeregen tash chokyrda gyna tuktalyr //The stone that has rolled down the hill can only stop in the pit.

The proverbs reveal that the Tatars' ancestors considered the Ural Mountains to be the highest, compared to none: Ural taudai tau bulmas, Ural asha su bulmas // There is no such mountains as the Urals, There's no water passing through the Urals (here: water =the river). This is explained by the fact that the Tatars in their nomadic life did not meet higher mountains, whilst The Oslan mountain was considered to be easily passable: Oslan tavy hetle tau zhinel buldy, ber uch tufrak avyr buldy // The mountain was easily passable, just like Oslan, the soil in the palm was heavy.

The lexical item "tau // mountain" is also found in a few names of the Tatar settlements. With its phonetic version it is represented in all Turkic languages, where is is also used to mean a "mountain". There are townships Biektau in Vysokogorskiy and Yutazinsky Regions, a village village in Rybno-Slobodskiy Region, called Biektau; Tashkabak village in the Upper Uslon region of the Republic of Tatarstan.

Even though the territory of the modern Tatars habitat has no seas, the word dingez // sea is commonly used in the Tatar proverbs. Like a mountain, it is immense, endless: Dingez vak elganyda kyre kakmyi // The sea does not reject a small river; dingezde bulmagan - kurkynych kurmegen [6: 368] // Who hasn't been at sea, has not seen the dangers; Dingezne mahkta, koryny tapta // Praise the sea, walk on the land; Dingeznen suyi ni echelmes ni kichelmes // One cannot drink the water in the sea, nor can swim the sea.

Compared to other geographical names, hydronyms are considered to be the most ancient. Rivers, ponds and springs were important for people's life, so people were willing to build their homes in the most favourable locations: along the banks of rivers, lakes and other water sources. The locals created a thoroughly developed system of geographical terms for various water objects features. The vocabulary related to naming the water bodies is extremely diverse and heterogeneous. Such hydronyms as: elga//river, kul // lake, sazlyk // swamp, koye// well and others are widely used.

Compared to the sea, the river is described as a more tranquil natural phenomenon. In paramiology it is relayed via such words as elga and idel: Elga kypme borgalansa da, dingezgə tosher // No matter how long the river winds, it still falls into the sea; Idel suyi bal bulsa da, ilge zhitmes // Even if the water of the river becomes honey, the country will still 
lack it; Idel ber, chishmese men // The Volga is one, but it has thousands of sources. In the latter, Idel as a lexical item, can be interpreted in two ways - as a river, and as the Volga river; even though the semantics is the same, for today's reader the latter meaning would be closer. In proverbs we also find the names of such rivers as Kama, Vyatka, Ural, emphasizing people's pride of their water resources: Nokratnyn ber tashy komesh, berse bakyr // One stone of the Vyatka is made of silver, another is made of copper; Chulmanny chumanga utyrap kichmilər // Kama is not swum across in the box; Zhaek bashtan zhil isse, yaz bulsa da, kysh bulyr // If the wind comes from the Urals, it will turn the spring into winter.

Elga "river, stream" with its versions: zhalga, dzhylga, yilga, ilga. Compare: khalkha (Buryat), zhalga (Mongolian) "gully, ravine, dry bed", delge (Evenk) meaning "ravine, river bed, log, gully". In the ancient Turkic dictionary: qory jalga refers to the geographical name of a place in the Central Asia near Fergana, and has become synonymous to wilderness, to the middle of nowhere. "The etymological dictionary of the Turkic languages has a variety of meanings: "river, river flowing into a ravine, mountain river, creek, stream, ravines, gullies, gorge, narrow stony road, channel, trough, meadow". This geographical term is believed to have been borrowed from the Mongolian language.

River, springs, lakes, marshes, as well as their features are widely used in many settlement names. For instance, the hydrological term elga "river" is reflected in Oly Elga village name in Rybniy-Sloboda region, the village Kushelga in Zainsk area, Elgabash in Muslimovskiy and Mamadysh regions, etc.

There is also a concept of kory elga // dry river, implying gullies. Such phrase in the form of an oxymoron is widely used in colloquial speech and proverbs: Kory elgaga batyrdym // sink in a dry river.

Among water resources we also find such items as koye // well, kul // lake, conveying different meanings. For example, implying an abundance of something: Kul tamchydan zhyela // A lake is filled drop by drop; or a remorse: Koega tash tashlan zhinel, aluy avyr // It is easy to throw a stone into a well, but it is hard to get it back; or tolerance: Koeda da su bete //Even the well gets dry, etc.

The concepts chokyr // pit, tyben zhir // lowland, kalkulyk //upland are to signify the landscape features and indicate its diversity reflected in the following proverbs: Kurmegen zhirnen chokyry kүp // The unfamiliar terrain has many pits; Tuben zhirde ber tube uzen thauga sanagan // A roof in the lowlands imagines itself to be mountain; her kalkulyknyn ber chokyry bar // Every hill has its own pit, etc.

The landscape takes on a certain colour due to the natural phenomena. The temperate continental climate of habitat is rich enough in natural phenomena, this these natural characteristics are reflected in the aphoristic genres of folklore. For instance, Ləysən - rehmet yangyry // Laysan is a gratitude rain; Lejsen suyn zhide el saklasan enzhege everelə // If one keeps Laysan waters for seven years, it turns into pearls. These are the proverbs about the first spring rain and Laysan was considered to be a nobility rain, purifying after hibernation.

It should be also noted the Tatar children's folklore addresses rain, as well as special rituals, with a prayer to rain soon.

Salavat kupere // the rainbow after the rain is an especially good sign and in the Tatar language it literally means "a praiseful bridge." The Tatars liked to tell fortune by the rainbow and there are a lot of signs on this subject: Salavat kuperenen ber yagy tuben kurense, ayaz bulyr // If one side of the rainbow appears to be lower than the other, the day will be clear; Salavat kupere auga toshse, yavymga bulyr // If a rainbow descends into the water - it will rain, etc.

Every natural phenomenon is associated with certain features reflected in the folklore texts among other resources. For instance, rain, snow are signs of good luck, harvest: Yangyr yausa - zhirge may // If it rains, the soils gets its oil; Ekren yangyr ute chylata // Slow rain causes a lot of wetness; Yangyr artynnan yuanych// Happiness comes after the rain; Kar kup bulsa, igen unar // Lots of snow brings a rich harvest; Kara erese de, bozy kala // The snow mels, but ice remains. The first spring and autumn rains were of a particular meaning: Kozge yangyr - maily yangyr// Autumn rain is an oily rain.

Wind is a symbol of news, both good and bad, so wind was reffered to with caution: Zhil kaidan, bolyt shunnan/l Where there's a wind, there's a cloud; Zhilge tuzan iyarer // The wind brings the dust; Zhilneke - davylga // Wind brings storm. A cloud was associated with a message, it scared people: Ber bolyttan yangyr da yava, yaava kar da, boz da yavar // Even one cloud can bring rain, snow, and hail; Bolyt kulegesene tayanych yuk // Do not trust the shadow of a cloud; Bolytsyz yangyr bulmas // It does not rain without a cloud.

Of course, all these features are quite relative, and as it has been previously mentioned, they are all focused on a human, people's actions and external qualities, thus the ancestors through their observations and skills, warn us of the impending.

As seen from the example, the paremias characterizing nature and landscape are very diverse. Depending on the keywords, their meanings can change completely. There's a large number of aphoristic texts describing nature - in a great variety of events and situations in life. This shows an importance of this concept to native speakers. 
It was very interesting to discover that sometimes the same natural phenomenon is used in a totally opposite meaning in proverbs. However, there are absolutely identical paremias with different components of animate or inanimate nature emphasizing the same trait. The diversity seems to be explained by differences in people's views concerning the same phenomenon, by people's attitude towards them [10]. It also depends on the time of utterance, personal likes and dislikes, etc., as well the degree of importance of the "object" to a native speaker.

\section{Conclusions}

Findings: in the Tatar paramiology an individual's freedom is highly valued, along with the unity, the diligence, hard work, courage. However, we also observe the reflexion of obedience to the fate, dependance on the Almighty and the vagaries of nature.

In the life of our ancestors, the natural environment was of great importance. Choosing favourable places for their homes, people often settled near forests, mountains or rivers. Therefore, these important natural objects originally got their names as geographical terms, which later evolved into the name of geographical objects.

The geographical position and the historical development of the Turkic-Tatar people defined the specificity of landscape vocabulary which is most evident in functioning of these words as metaphors, in creation of different images.

\section{References}

Yusupova A.S., Galiullina G. R., Denmukhametova E.N. Representation of national mentality in Turkic-Tatar vocabulary. Life Sci J 2014;11(7):506-508] (ISSN:1097-8135). http://www.lifesciencesite.com. 66

Denmukhametov, R.R., Zjablova, O.V., Shtanchaeva, M.R. Development factors of Kazan region recreation area. Life Science Journal. Volume 11, Issue 11, 2014, Pages 317-320.

Denmukhametov, R.R., Zjablova, O.V. Geodemographic situation in the Republic of Tatarstan. World Applied Sciences Journal. Volume 30, Issue 11, 2014, Pages 1684-1688.

Gabdrakhmanov N.K., Rubtzov V.A., Mustafin M.R., O.V. Pratchenko. Geodemographic Potential of the Republic of Tatarstan: Analysis, Evaluation, Territorial Differences // Mediterranean Journal of Social Sciences, Vol 5 No 24, 2014, pp.278-285.

Biktimirov N., Gabdrakhmanov N., Rubtsov V., Mustaphin M., Arzhantseva N. Peculiar Features of the Tatar People Migration on the Territory of Tatarstan // Mediterranean Journal of Social Sciences, Vol 5 No 24, 2014, pp.267-272.

Aminova A.A., Gilazetdinova G.Kh., Edikhanov I.Zh. Problems of Ethnocultural Identity and Cross-Language Communication // Journal of Language and Literature 2014; 5(3), 39-42

Zamaletdinov R.R. The lexicon and its reflection in the inner world of the individual (on the basis of the Tatar language) / G.F. Zamaletdinova, R.S. Nurmukhametova, M.R. Sattarova // Journal of Language and Literature 2014; 5(4), 333-335.

Mugtasimova G.R., Nabiullina G.A., Denmukhametova E.N. Paremiological Fund of the Tatar people in the ethno-linguistic aspect. Life Sci J 2014;11(11):409-412] (ISSN:1097-8135). http://www.lifesciencesite.com. 69

Nabiullina G.A., Denmukhametova E.N., Mugtasimova G.R. The linguistic characteristics of Tatar Paroemiae. Life Sci J 2014;11(5):559562 (ISSN:1097-8135). http://www.lifesciencesite.com. 85

Yusupova A.S, Denmukhametova I.N.,Nabiullina G.A. and Mugtasimova G.R. Features of the Language of Tatars Living in China /I Middle-East Journal of Scientific Research 17 (2): 168-172, 2013.- ISSN 1990-9233. IDOSI Publications, 2013. DOI: 10.5829/idosi.mejsr.2013.17.02.12181.

Gaisin, I.T., Beketova, S.I., Gaisin, R.I. Competence-based approach as an effective way to increase the level of training of geographers in universities // Life Science Journal 2014;11(11 s)C.166-170.http//www.lifesciencesite.com

Biktimirov, N.M., Gaisin, R.I., Gaisin, I.T. The use of new methodologies for demographic investigations in national-territorial subdivisions of Russia. Life Science Journal, 11 (SPEC. ISSUE 8), pp. 194-197

Safiullin, N.Z., Gafurov, I.R.,Safiullin, L.N., Odintsova, J.L. Education system of the world: Modern trends. Mediterranean Journal of Social Sciences, 5 (18 SPEC. ISSUE), pp. 91-94.

Safiullin, N.Z., Gafurov, I.R.,Safiullin, L.N., Odintsova, U.L. Modern information resources in education. Mediterranean Journal of Social Sciences, 5 (12), pp. 113-116. 